\title{
The future of pharmaceutical R\&D: somewhere between open and reverse innovation?
}

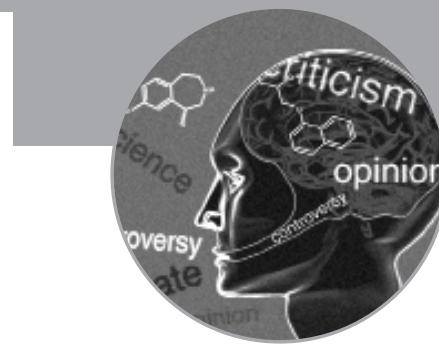

\author{
"Open innovation is a paradigm that assumes companies should capitalize on external and internal ideas/paths to market, as \\ they seek to advance their technologies."
}

The pharmaceutical industry has now entered a period of significant uncertainty and transition characterized by higher R\&D costs, depleted pipelines and financial restriction to perform innovative research. The global credit crunch exacerbates all this with more and more layoffs and research budget cuts; but major crisis can sometimes produce major opportunities. New business models such as open innovation may help solve the so-called pharmaceutical 'productivity paradox' via the sharing of risk, cost and intellectual property through R\&D strategic alliances involving all kind of innovators, such as pharmaceutical, biotechnology, academic drug-discovery centers and clinical research organisations. Other models such as reverse innovation may provide another solution of choice to address the huge $\mathrm{R} \& \mathrm{D}$ costs in the so-called developed countries. Pharmaceuticals may want to place bets in more attractive geographical zones that will necessitate major $\mathrm{R} \& \mathrm{D}$ adaptations.

\section{Pharmaceutical R\&D business is under attack}

The pharmaceutical industry is presently facing numerous challenges, such as a slowdown in successful innovations, increasing research costs, decreasing revenues due to patent expirations, and the huge expense to bring a drug to the market as a result of enhanced regulatory hurdles. While mergers and acquisitions as well as heavy investments in generic and/or over-the-counter activities are some of the pharmaceutical strategies to overcome the impact of the current economic downturn, new ways of organizing innovative activities may induce major changes in the way pharmaceutical industry will run its $\mathrm{R} \& \mathrm{D}$ business in the future [1] Internationalization of $\mathrm{R} \& \mathrm{D}$ and organization of $\mathrm{R} \& \mathrm{D}$ around technological platforms nowadays play a major role in the $\mathrm{R} \& \mathrm{D}$ strategies of many pharmaceutical companies. Another new approach aimed at helping to address the productivity paradox (partly owing to the pharmaceutical industry's perceived lack of innovation), that has attracted considerable attention over the past few years is the 'open innovation' (OI) model.

\section{Open innovation for the \\ pharmaceutical business}

Open innovation is a paradigm that assumes companies should capitalize on external and internal ideas/paths to market, as they seek to advance their technologies [2]. Buying or in-licensing processes and patents from other companies as well as selling or out-licensing intellectual property rights may become the way forward to profitability. The ability to actively take part in $R \& D$ projects shared with someone else's budget, to conduct risky innovative research at lower levels of cost, risk and resources, will continue to become more strategic in a future dominated by the financial situation. While such a model has already been adopted by the informatics, food and aircraft industries, the pharmaceutical industry has only just started to implement OI as part of its corporate strategy [3]. Pharmaceutical OI has been fostered and cultivated by internet and social networking platforms, which have allowed enhanced and global information exchange between companies and innovators located all over the world. Lilly, for example, started OI by developing collaborative web-based platforms such as Innocentive [101], and recently found a nice way to potentially fill its pipeline with innovative compounds via the phenotypic drug-discovery initiative [102]. Attracting worldwide partners via the establishment of internal web portals started with Procter \& Gamble's 'P\&G Connect + Develop', where people were invited to submit their ideas and commercial

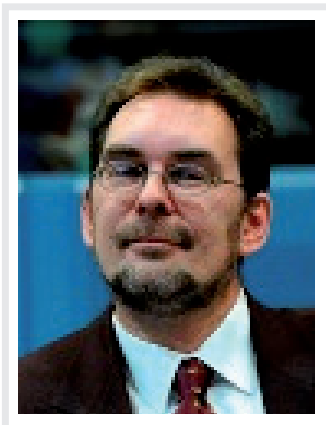

Patrice Talaga

Director of Chemistry Outsourcing at UCB, Chemin du Foriest, B-I420 Braine-l'Alleud, Belgium

Tel.: +32 23862727

Fax: +32 23862704

E-mail: patrice.talaga@ucb.com 


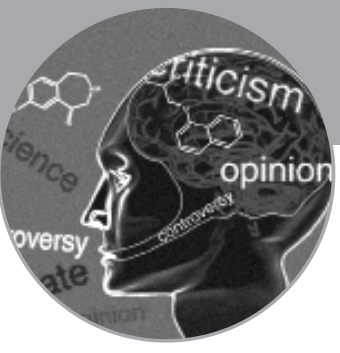

opportunities based on P\&G needs. Pfizer recently adopted the same model by launching the 'Pfizer Incubator' platform [103]. More radical innovations are based on the establishment of high-tech campuses such as that built by Phillips some years ago, which presently hosts more than 40 companies and institutes working together in the development of new technologies [104]. Recently, pharmaceutical companies like Janssen Pharmaceutica and GlaxoSmithKline (GSK) announced the creation of similar ecosystems in the near future. Strategic drug-discovery and/or-development alliances are becoming more and more part of the pharmaceutical OI landscape; for example, the alliance between Shionogi and Purdue is an interesting case study of OI that nicely illustrates the way in which companies can share their IP and jointly generate profit [4]. Overall, OI could be a valuable model for pharmaceutical companies [5]. Opportunities to gain access to worldwide innovations and solutions aimed at decreasing $R \& D$ costs through risk-sharing partnerships, should drive the implementation of OI within pharmaceutical companies. Because OI uses sharing of IP as the 'currency' to drive collaborative research, it should help to decrease the initial $R \& D$ financial investments and, thus, probably allow pharmaceuticals to continue investing in risky innovative R\&D activities. Thus, the economical downturn may well be one of the principal drivers that pushes companies such as Johnson \& Johnson, GSK or sanofi-aventis, to proactively adopt the OI business model as a new way to fill pipelines with innovative drugs; moving away from the traditional 'merger and acquisition game'.

\section{“Opportunities to gain access to worldwide} innovations and solutions aimed at decreasing $R \& D$ costs through risk-sharing partnerships, should drive the implementation of $\mathrm{Ol}$ within pharmaceutical companies."

In practice, however, some companies will face a difficult time adopting such a business model mainly due to control sharing that seems particularly challenging for those that are used to having their own way in running their ecosystems. A successful pooling of R\&D activities looks possible provided best business practices are implemented before the start of the collaboration. Thus, some of the key points to consider in order to fully 'open the collaboration' will include:
- The search for a partner with a similar view on practicing OI;

- The creation of an adequate governance where all committees include equal representation by the partners, and which will be given full empowerment to control the direction of research within the network;

- The nomination of alliance managers who will help implement consistent and transparent daily communication between researchers and managers;

- The mutual agreement to implement a creative, efficient and open collaborative environment, which will be crucial to enable real knowledge sharing;

- The creation of a communication system allowing real-time data sharing;

- All partners should agree on a common data format and design to allow coherent and synchronized data management;

- A clear understanding of IP sharing by defining well before the start of the partnership what type of proprietary data could be shared.

Some recently published papers provide useful information about good practices in the field of OI $[4,6,7]$.

It is also worth mentioning that $\mathrm{OI}$ can be adopted to help deliver new and better medicines in emerging economies. Some companies, such as GSK, recently announced the use of OI to deliver new drugs for neglected tropical diseases in the world's poorest countries. Could OI be an introduction to reverse innovation (RI) (FIGURE I)?

\section{Reverse innovation for the pharmaceutical business?}

According to Wikipedia, RI is "a term referring to an innovation seen first or likely to be used first in the developing world before spreading out to the industrialized world". More and more companies are presently developing products in China or India and then distributing them globally. The process usually starts by focusing on needs and requirements for low-cost products in emerging countries. Once products are on the market, they are then sold in other parts of the world at low prices, which creates new markets and uses for these innovations. For example, General Electric (GE) is now selling products (portable ultrasound devices) in the USA that were originally built by GE 


\section{(A) Globalization}

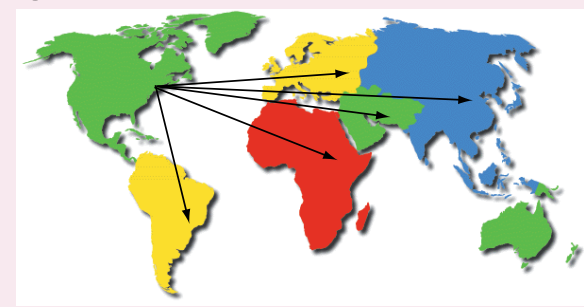

Innovate at home and sell worldwide

(C) Local innovation

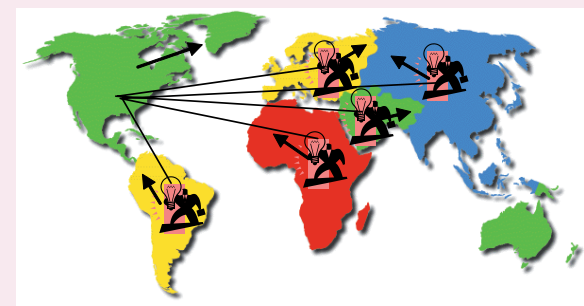

Innovate and develop 'in country, for country'
(B) Glocalization

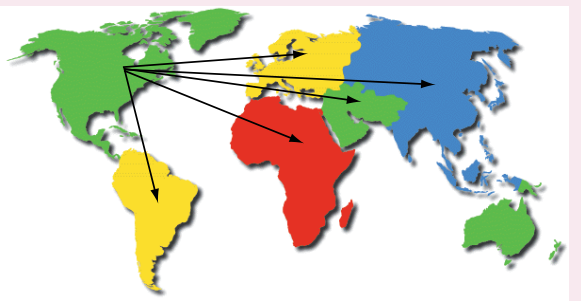

Innovate at home, adapt to meet local needs

(D) Reverse innovation

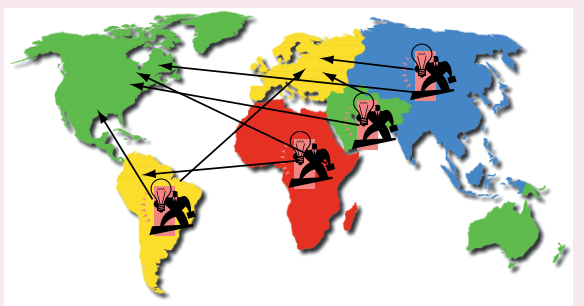

Innovate and develop 'in country, for the world'

Figure 1. The (historical) steps to reverse innovation.

Healthcare for doctors in India and China [8]. The success of such a model is based on the socalled 'local growth team model', which relies on the following fundamental principles:

- The local growth teams need the power to develop their own strategies, organizations and products based on a local-market focus;

- New offerings must be built from the ground up;

- Objectives, targets and metrics must be customized according to local standards. Support from the companies' global resources/expertise is mandatory;

- Local growth teams have to report to the highest level of the organization only.

Numerous examples across various industries (e.g., Nokia, Microsoft, Tata Motors and $P \& G)$ highlight an interesting emerging market strategy that could help companies to survive. Emerging markets such as India, China and Latin America are the new mass markets of the world. Once tested and adopted locally, products developed using such a strategy could be taken global. To be successful, this strategy may require some pioneering innovative applications for such products intended for commercialization in developed parts of the world. Most importantly, successful companies will have to make sure they empower their local teams and that they launch high-value projects in order to avoid a stagnation of the emerging country-based $\mathrm{R} \& \mathrm{D}$ center. Establishing a common language, implementing a global talent strategy and leveraging local partners (without risking IP leakage) will help to 'make it happen'. Could such a model be applied to pharmaceuticals?

\section{Future of (European) pharmaceutical R\&D}

Before addressing this question, let us highlight some facts and trends concerning the current pharmaceutical business landscape:

- The pharmaceutical industry is suffering heavily from the financial crisis;

- The return on capital on R\&D investment has been falling for years. Most of the big pharmaceutical companies have already picked the 'low hanging fruits';

- There is too much emphasis, especially in Europe, on keeping prices low in the short term and not enough on setting prices that would foster innovation in the long term. The USA may face the same situation in the future with its recent move towards the adoption of a more European style of health care;

- The time needed to get drugs onto the market is increasing due to there being more and more demands to satisfy regulatory agencies; 


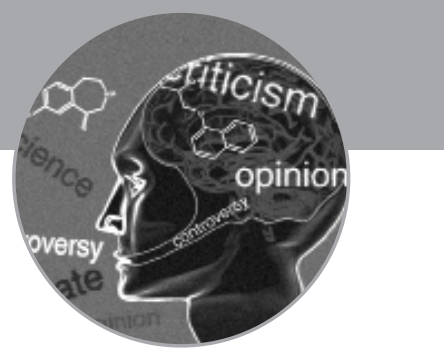

- More and more stakeholders (e.g., EMA, US FDA and healthcare agencies such as NICE) have the decision power to get a drug approved and properly reimbursed;

- The cost to launch a drug can nowadays easily exceed US $\$ 1$ billion;

- In certain situations (i.e., for CNS diseases), only Phase III clinical trials will give a sound proof of concept for the efficacy of a certain drug. $R \& D$ costs to launch innovative drugs within therapeutic areas with high attrition rates can adversely affect the company's business.

One obvious question arises: "how can we launch innovative products when the cash we can earn is just not meeting our spending needs?"

\section{"Emerging markets such as India, China and Latin America are the new mass markets of the world."}

Open innovation may help address this question through the sharing of IP, resources and, most importantly, costs, to launch real innovative products wherever they come from. But it will not solve the issues related to the so-called 'regulatory burden' that makes it too expensive for a drug company to continue $\mathrm{R} \& \mathrm{D}$ activities for certain therapeutic areas. GSK very recently took the radical step to reduce the size of its European R\&D operations by stopping discovery research into certain areas of neuroscience and by predominantly focusing on neurodegenerative disorders. Interestingly, in 2007 GSK announced the creation of a research facility in Shanghai that should become one of its largest research centers in the world. It is said that the planned facility would perform the entire range of drug-development activities, rather than only drug discovery or clinical trials. China was selected as a location for R\&D into neurodegenerative diseases for various reasons, such as talent pool access, strong presence of local neuroscience research and, last but not least, the existence of a commercial organization, vaccine business and manufacturing capabilities [9]. Another example of what could be related to reverse innovation is the recent announcement of the acquisition of WuXi Pharma Tech by Charles River Laboratories [105]. Will this become a new 'reverse innovation merger' model that may generate much better return on investment...? Could such a trend help convince European and/or US venture capitalists to shift funding from western countries to emerging ones?
It may be speculative to make a link between these facts and the concept of reverse innovation applied to the pharmaceutical business.

The pressures facing large pharmaceuticals in Europe are coming from all sides. Patent expiry, reduced funding for innovation, regulators who set the bar higher and higher, and approval and pricing issues as payers seek to limit reimbursement are all hampering the $R \& D$ business in developed countries. With the current internationalization of $\mathrm{R} \& \mathrm{D}$ activities, the growing eastern talent pool, the numerous clinical trials currently going in China and India, and the creation of $\mathrm{R} \& \mathrm{D}$ organizations involving more or less all activities of the pharmaceutical value chain in emerging countries, it is tempting to speculate that there may be a link. Thus, one could speculate that a company announcing the launch of an innovative anti-Alzheimer's disease drug invented and made in China, could potentially make a huge profit by selling it in the US and/or in Europe at a much better price, because of the lower initial investments. If this trend becomes established, US and EU companies could soon find themselves in a sales and marketing role for new drugs coming from the east.

Of course, India and China as future $R \& D$ centers stocking up western countries with innovative drugs is at present only a dream or a nightmare depending on one's point of view. No successful 'business case' has been reported up to now. Moreover, reverse innovation in the field of pharmaceuticals will require solutions to some of the well-known problems found in R\&D outsourcing, such as IP theft, patent infringement, lack of appropriate skills, lack of relevant biostatistics and clinical trials data management know-how, local bureaucratic and regulatory hurdles. In all cases, the current global economic crisis presents a double-edged opportunity for pharmaceuticals: reducing the $\mathrm{R} \& \mathrm{D}$ costs/workforces (and thus, potentially, know-how) in the developed countries, while accelerating the growth and $R \& D$ expertise in emerging economies. It may be difficult to make the right choice but we will need to have enough courage to take a position. This means rethinking business models, a willingness to implement major changes and rapidly solving the problems of drug pricing and regulatory issues. The future of western pharmaceuticals depends on it!

\section{Acknowledgements}

The author would like to thank the reviewers who provided very pertinent comments and suggestions. 
Financial \& competing interests disclosure

The author has no relevant affiliations or financial involvement with any organization or entity with a financial interest in or financial conflict with the subject matter or materials discussed in the manuscript. This includes employment,

\section{Bibliography}

1 Paul SM, Mytelka DS, Dunwiddie CT et al. How to improve R\&D productivity: the pharmaceutical industry's grand challenge. Nat. Rev. Drug Discov. 9, 203-214 (2010).

2 Chesbrough HW. Open innovation: the new imperative for creating and profiting from technology. Harvard Business School Press, Boston, MA, USA (2003).

3 Talaga P. Open innovation: share or die... Drug Discov. Today 14, 1003-1005 (2009).

4 Yamaguchi E. Shionogi/Purdue strategic discovery alliance with synchronicity and serendipity - case study of open innovation. Les Nouvelles 72-78 (2009).

5 Hunter J, Stephens S. Is open innovation the way forward for big pharma? Nat. Rev. Drug Discov. 9, 87-88 (2010).

6 Vargas G, Boutouyrie B, Ostrowitzki S, Santarelli L. Arguments against precompetitive collaboration. Clin. Pharmacol. Ther. 87, 527-529 (2010).

7 Wagner JA, Prince M, Wright EC et al. The Biomarkers Consortium: practice and pitfalls of open-source precompetitive collaboration. Clin. Pharmacol. Ther. 87, 539-542 (2010). consultancies, honoraria, stock ownership or options, expert testimony, grants or patents received or pending, or royalties.

No writing assistance was utilized in the production of this manuscript.

8 Immelt JR, Govindarajan V, Trimble C. How GE is disrupting itself. Harv. Bus. Rev. 3-11 (2009).

9 Hughes B. New and Analysis. An audience with Jingwu Zang. Nat. Rev. Drug Discov. 8, 352 (2009).

\section{- Websites}

101 Innocentive: one of the first open innovation web portals www.innocentive.com

102 Lilly's PD2 initiative www.pd2.lilly.com

103 Pfizer's open innovation web portal www.thepfizerincubator.com

104 Philip's open campus radical innovation model www.hightechcampus.nl

105 Charles River - WuXi merger announcement www.criver.com/SiteCollectionDocuments/ WuXi_Press_Release.pdf 